\title{
Da proa da Canoa: Por uma etnografia do movimento indígena em Tefé"
}

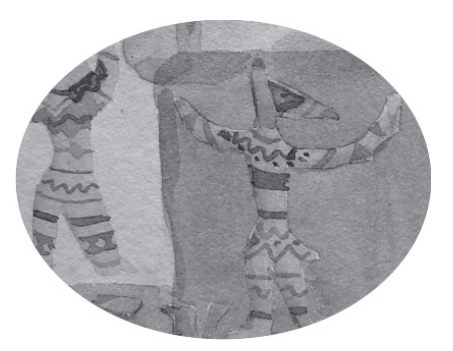

Benedito do Espírito Santo Pena $\mathrm{Maciel}^{7}$

\section{Resumo}

Este artigo procura traçar um perfil histórico e etnográfico, bem como discutir o caráter afirmativo e identitário do Movimento Indígena na região de Tefé. Tomamos como referência para este trabalho o período de 1992 a 2003, quando o Movimento Indígena passa por importantes mudanças em seu caráter afirmativo e organizacional, apontando para maior autonomia em relação a outros agentes interculturais.

Palavras-chave: Amazônia. Movimento Indígena. Região de Tefé.

\begin{abstract}
This paper aims to outline a historical and ethnographical profile of Native Movement in Tefé as well as discuss the identity and affirmative characteristics. The referential period used in this paper is from 1992 to 2003, when the Native Movement passes through important changes in its organizational and affirmative character, pointing out the autonomy increase in relation to other intercultural agents.
\end{abstract}

Keywords: Amazonia. Native Movement. Tefé Region

7 Mestre em Sociedade e Cultura na Amazônia pela Universidade Federal do Amazonas e professor de Antropologia Indígena do Instituto Natureza e Cultura da mesma universidade. 


\section{Introdução}

Os estudos das relações interétnicas, fronteiras étnicas e Movimento Indígena no Médio Solimões vêm sendo realizados desde a década de 1980 por Priscila Faulhaber (1987a; 1987b; 1997; 1998). Em O Navio Encantado: etnia e aliança em Tefé e $O$ Lago dos Espelhos, a autora traça um quadro bastante completo dos discursos dos agentes que atuam na fronteira, como: Igreja, índios, Estado, comerciantes e outros agentes políticos. A relação e a intervenção dos diferentes agentes do Estado com os povos indígenas durante a história recente do Médio Solimões, segundo Faulhaber, têm uma tendência clara para a homogeneização dos grupos étnicos. Porém, essa tendência tem encontrado por parte dos índios uma reação ou uma "resistência", “...onde persistem as diferenças étnicas entre, Miranhas, Cambebas, Mayorunas, Caixanas, Cocamas, Canamaris, etc...” (1998, p. 72).

Em relação ao Movimento Indígena, a autora destaca a existência de pelo menos duas diferentes tendências - uma mais ligada à atuação dos agentes do Estado e, outra, ligada à atuação da Igreja -, mas em algumas questões como saúde e educação, existe uma coalizão de interesses dos índios, em que estes acabam superando tais diferenças e contradições fazendo com que o Cimi(Conselho Indigenista Missionário) e a Funai (Fundação Nacional do Índio) conjuguem suas ações (FAULHABER: 1998: 73).

A criação da Uni-Tefé, no final dos anos de 1980, pode ser entendida como um esforço dos índios no sentido de unificarem suas lutas no Médio Solimões, frente a tantos "agentes interculturais" - para usar um termo de Cardoso de Oliveira (1978, p. 93) - cujas propostas são oriundas de diferentes tendências políticas. Isso levanta alguns problemas de ordem política para os povos indígenas, por exemplo: como levar em frente uma organização indígena constituída por várias etnias em diferentes situações de contato? Como construir uma representatividade política desses grupos dentro da Uni-Tefé e desta com a sociedade nacional? Uma tentativa de resposta a estas questões nos remete à discussão não somente da "representatividade", mas também do "poder" no movimento indígena. Sobre que parâmetros esse "poder indígena" é gestado e constituído dentro da Uni-Tefé? Pode-se falar em um "modelo indígena" ou em um "modelo branco" de organização? Ou numa "reinvenção", a partir da problemática do contato e das relações interétnicas? 


\section{2- Antecedentes históricos}

A existência do Movimento Indígena na região do Médio Solimões é mais antiga que a existência da própria Uni-Tefé. Desde o final da década de 1960 os índios Miranha das aldeias de Miratu e Méria se articulavam para garantir suas terras, melhoria na área de educação e agricultura. Lino Cordeiro, índio Miranha da aldeia Miratu, foi um dos principais líderes indígenas da região no início do Movimento. Em 1969 foi para Manaus servir ao Exército, trabalhou na construção civil, tornando-se membro do sindicato da categoria tendo assumido inclusive o cargo de 2 . $^{\circ}$ Secretário. Como sindicalista, viajou para várias regiões da Amazônia e, observando a realidade nesses lugares visitados, passou a refletir sobre a questão indígena e sobre a realidade de sua própria aldeia:

... Fiz algumas viagens. Fui pra Roraima, Rondônia, Amapá... E eu comecei a descobrir nessas minhas andanças que, de repente, Miratu tinha tanta coisa, não só o Miratu, mas o interior em si. Tinha tanta coisa pra ser feita, que precisavam de mim, talvez não de mim, mas do meu trabalho. Então isso me levou a fazer parte do Movimento e fez com que eu voltasse, deixasse tudo o que tinha e voltasse pra aldeia de novo... (CORDEIRO, 2002).

Lino voltou para Miratu em 1975 e passou a articular o Movimento Indígena na região. Relata que uma de suas primeiras preocupações, além da garantia da terra, era a erradicação do analfabetismo. Para desenvolver os projetos de educação era necessário que a aldeia tivesse energia elétrica. Por isso, Miratu foi uma das primeiras comunidades de Tefé ${ }^{(1)}$ a ter um motor a diesel e um gerador de energia elétrica. A partir de 1978 os Miranha começaram a se articular com os Mayoruna da aldeia de Marajaí e com os Cambeba da aldeia de Jaquiri. Entre 1978 e 1979, antes do Movimento ter uma coordenação mais permanente, trabalhavam com Lino: Pagão, índio Mayoruna de Marjaí; Gercino, índio Miranha de Méria e Valdomiro Cruz, índio Cambeba de Jaquiri.

Mas, é de meados da década de 1970 em diante que os índios começam a organizar os mutirões inter-comunitários ou "ajuris", como é conhecidos na 
região de Tefé o trabalho comunitário que reunia duas ou mais comunidades para realizar tarefas coletivas. Segundo Carvalho Franco (1976, p. 29. apud FAULHABER, 1987b, p. 89), o mutirão

[...] consiste em uma forma cooperativa de trabalho e, como se sabe, é convocado quando se trata de realização de benfeitorias de interesse coletivo (caminhos, capelas, etc.), ou quando tarefas têm de ser realizadas como requisitos de celeridade que ultrapassem os limites do trabalho doméstico, (plantio, colheita, derrubada, construção de casa etc.) [...] baseado na prestação voluntária e gratuita de serviços entre pares".

Essa prática foi utilizada pelas aldeias para honrar suas dívidas de financiamento da safra, para conseguir objetos ou bens de uma determinada aldeia ou de uso comum, para construção de uma canoa ou casa comunitária e também para festejar uma data importante (aniversário da comunidade, festa de um santo, etc.). Essa forma de trabalho incentivada pela Igreja Católica em Tefé através do MEB (Movimento de Educação de Base) ${ }^{(2)}$ e da Pastoral Indigenista, vai se constituir um dos pilares do Movimento Indígena, sobretudo durante a década de 1980.

A Uni-Tefé constituiu-se numa organização juridicamente reconhecida em 1993. Neste ano com assessoria da Pastoral Indigensita de Tefé, a organização discutiu e elaborou seu primeiro Estatuto, no qual a entidade é definida como: "... uma entidade civil, sem fins lucrativos, filantrópica, apartidária, sem vinculos com instituições religiosas e que representa os povos e organizações indígenas do Médio Solimões e afluentes".

A discussão para a aprovação do Estatuto da Uni-Tefé ocorreu durante todo o ano de 1993, seguindo um processo pedagógico dividido em cinco etapas: 1) - elaboração da proposta preliminar pela Pastoral Indigenista; 2) - apresentação e discussão da proposta com a coordenação da Uni-Tefé; 3) - discussão com os índios do Médio Solimões e Japurá em duas Viagens de Articulação; 4) - discussão numa Assembleia Regional no Japurá e; 5) - discussão e aprovação numa Assembleia Geral reunindo as aldeias do Médio Solimões e Japurá.

A aprovação desse estatuto se deu num contexto em que os índios - especialmente a coordenação da Uni-Tefé - desejavam poder estabelecer 
parcerias por meio de projetos financeiros com diferentes agências financiadoras tanto do Estado como da sociedade civil e entidade estrangeiras, buscando, assim, uma autonomia financeira em relação à Prelazia de Tefé até então responsável administrativa e juridicamente pelos seus projetos financeiros.

Em 1995 a Uni-Tefé adquiriu um escritório na cidade de Tefé e passou a concentrar suas atividades administrativas e burocráticas. Antes dessa data a Uni-Tefé não tinha sede própria. Sua documentação ficava uma parte no escritório da Pastoral Indigenista na cidade de Tefé e outra parte na aldeia Jaquiri, onde se concentrava a maioria dos dirigentes da organização. As reuniões administrativas eram realizadas ora em Jaquiri ora em Tefé no escritório da Pastoral, mais neste que naquele, contudo, o centro político do Movimento era a aldeia Jaquiri, pertencente ao grupo Cambeba. Os índios se deslocavam para Tefé no barco "Capitão Fernandes" de propriedade da aldeia Jaquiri uma ou até duas vezes por semana para resolver problemas burocráticos; fazer contatos políticos com entidades de apoio e autoridades; divulgar os trabalhos da organização e a realidade indígena nas escolas e na Rádio Educação Rural de Tefé, através de um Programa de Rádio mantido pela Pastoral Indigenista. A coordenação da Uni-Tefé utilizava a rádio para informar as aldeias sobre o que acontecia "fora" e para articular reuniões, encontros e outras atividades do Movimento.

\section{3- Composição e organização da Uni-Tefé}

A Uni-Tefé, até pelo menos o ano de 2003, estava estruturada da seguinte maneira: uma coordenação executiva eleita a cada dois anos; uma coordenação local composta por um membro de cada aldeia, que seria, além do tuxaua, um braço da organização dentro das aldeias; um conselho fiscal composto por dois representantes eleitos em assembleia e a assembleia Geral. A Uni-Tefé possuía ainda as seguintes organizações membros: Amism (Associação de Mulheres Indígenas do Médio Solimões); Cija (Comissão Indígena do Japurá) que reunia os Miranha das quatro aldeias (Vila Nova, São Pedro, São José, Nova Estrela) da área indígena Cuiu-Cuiu, os Kanamari do Município de Maraã e os Maku do Município de Limoeiro.

A Uni-Tefé também se articulava com o movimento dos professores e de agentes de Saúde Indígenas, que não constituíam uma organização formal, 
mas que tinham momentos específicos de reunião, estudo, assembleias, oportunidade em que elaboravam propostas de trabalho para serem desenvolvidas pela Uni-Tefé.

Essa estrutura organizacional criada em 1993 sofreu nos dez anos seguintes poucas modificações. Esse modelo de organização adotado pelos índios no Solimões - que é também o modelo adotado em muitas regiões do País - trouxe muitas mudanças para o Movimento Indígena em Tefé. A primeira mudança era que pela primeira vez a Uni-Tefé se propôs a articular um movimento em todo o Médio Solimões e afluentes, os rios: Japurá, Juruá e Jutaí, atingindo os seguintes povos indígenas: Ticuna, Cocama, Cambeba, Miranha, Mayoruna, Kanamari, Deni, Kulina (Madijá), Katukina e Maku, numa extensão geográfica de $258.000 \mathrm{Km}^{2}$ aproximadamente. Mas essa articulação só vai se consolidar a partir de meados da década de 1990.

Figura 1: Mapa da área de abrangência atual da Uni-Tefé

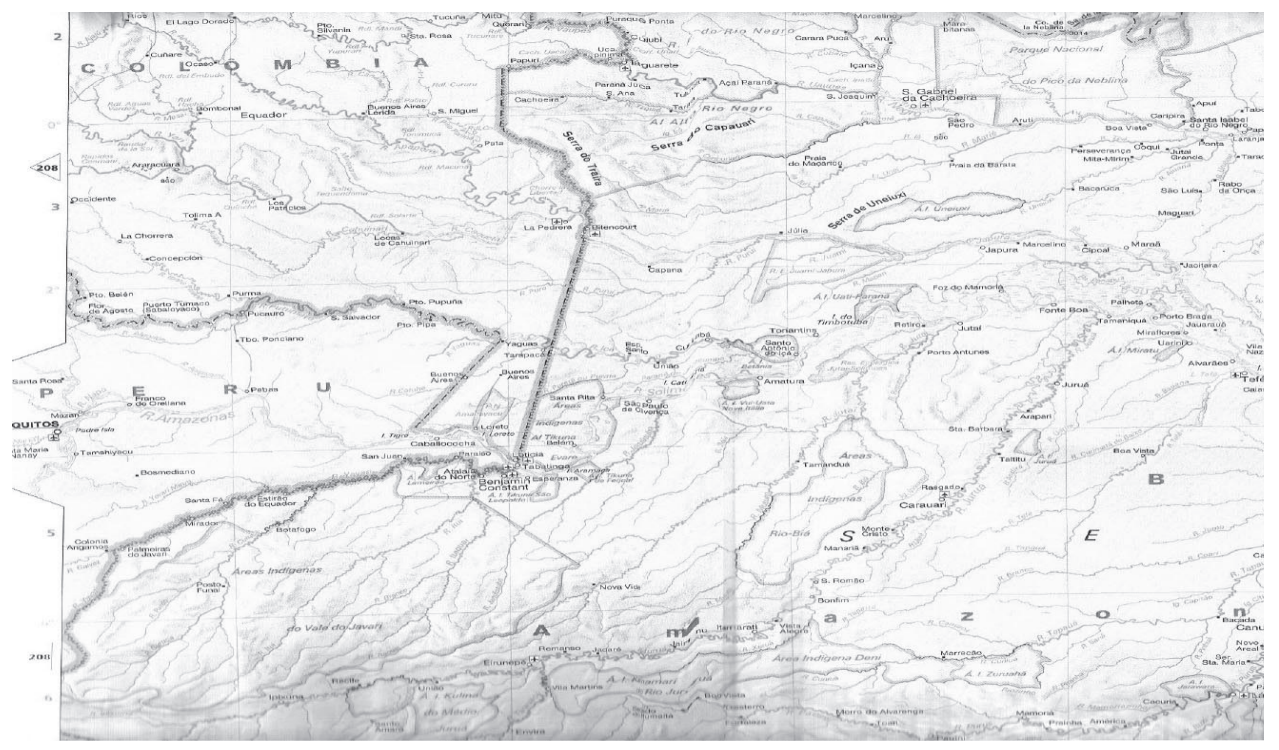

Fonte: Extraído de: Atlas 2000: a nova cartografia do mundo. Círculo do Livro e Abril Cultural, 1995, p. 210. Tratamento de imagem, Benedito Maciel. 


\section{4- Estrutura, dinâmica organizacional, relações interétnicas e articulação política na Uni-Tefé.}

Para articular o Movimento Indígena numa área dessa magnitude, a UniTefé definiu a seguinte estrutura e dinâmica organizacional:

a) Assembleia Geral, realizada a cada dois anos, tinha a função de avaliar o Movimento de forma ampla, a coordenação e outras instâncias da Uni-Tefé e realizar eleições gerais. Essas assembleias duravam de três a cinco dias e iniciavam, normalmente, com um levantamento dos problemas das aldeias e em seguida eram discutidas as soluções para tais problemas através de encaminhamentos práticos. Às vezes, havia estudos específicos de temas ligados à legislação e à política indigenista. Havia também um momento para a coordenação informar suas atividades, planos, projetos em andamento etc... As assembleias gerais eram momentos de analisar a realidade das aldeias, de procurar compreender o que estava acontecendo "lá fora" e de traçar estratégias coletivas de luta indígena.

Eram também momentos importantes de relações entre as diversas etnias, comunidades e aldeias, oportunidades não apenas para realizar as atividades formais do Movimento, mas para trocar experiências de trabalhos comunitários; realizar atividades de lazer: futebol, jogos de azar, danças tradicionais; estabelecer alianças; atenuar os conflitos pessoais e/ou entre as aldeias e os povos. Nas avaliações feitas no final das assembleias, todos realçavam o fato de ter "reencontrado os parentes" e a importância da união de todos.

Um fato importante que pude observar é que as assembleias se constituíam numa grande festa de confraternização indígena muito para além do aspecto formal a elas atribuído pelas demandas e expectativas externas. Cada aldeia sempre levava farinha, macaxeira, cará, banana, beiju, caiçuma, pajanaru e não faltava durante o momento da reunião o tradicional chibé. ${ }^{(3)}$

b) Assembleia Regional. Reunia representantes das aldeias de uma dada região (Médio Solimões, Japurá, Jutaí, etc.), realizada anualmente e tinha a função de avaliar a situação das aldeias, propor soluções para os problemas locais e encaminhar documentos e reivindicações dos índios para os órgãos competentes. A pauta dessas assembleias seguia a mesma ordem das assembleias gerais, mas elas se preocupavam em discutir apenas os problemas locais de cada região.

Assim como as assembleias gerais, as assembleias locais eram também momentos em que cada etnia procurava afirmar sua identidade diante da 
outra, procurando ganhar um melhor destaque no campo político dentro do Movimento. Na Assembleia Regional do rio Japurá, em 1993, observamos essa situação quando os Maku - considerados ainda como um grupo de "pouco contato" e que mantém sua língua materna - criticaram o fato dos Miranha da área indígena Cuiu-Cuiu - que estava iniciando o processo de reafirmação de identidade - não falarem mais a sua própria língua. Esse fato criou certa inibição entre os Miranha nos primeiros dias da assembleia, mas logo depois foi contornado pela coordenação. No final da assembléia os Miranha passaram a usar algumas "palavras indígenas" e exibiam pinturas em algumas partes do corpo. Porém, retrucaram: diziam também que os Maku "falavam muito atrapalhado" e "não se comportavam bem" na hora das refeições. Este fato aponta para aquilo que Cardoso de Oliveira (1976, p. 7) chama de identidade contrastiva.

Nas assembleias regionais do Médio Solimões, havia sempre a participação de lideranças convidadas de outras regiões e de não índios, o que ocasionava uma preocupação em mostrar a "cultura dos índios" para os participantes. $\mathrm{Na}$ ausência de caiçuma, não faltava um recipiente com chibé sobre a mesa principal da reunião, onde nos intervalos ou mesmo durante as seções todos tomavam essa bebida, cujo gesto significava aceitar as condições de "ser índio" e buscar ser aceito como tal pelos demais. Em todas as ocasiões que presenciamos, André Cruz, índio Cambeba influente no Movimento, sempre convidava os "parentes" e os demais participantes, inclusive os assessores e convidados não índios, para "tomar a bebida dos índios".

$\mathrm{Na}$ relação com os Maku e Kanamari do Japurá, os índios do Médio Solimões - e isso se valia, sobretudo, para os Cambeba e Mayoruna que coordenavam o Movimento - sabiam que o fato de dominarem o português, de viajarem "para fora", de conheceram a burocracia dos brancos, embora fosse determinante em muitas situações dentro do Movimento, principalmente na disputa pelos cargos de direção, que não bastava para garantir legitimidade no papel de "representar" os índios da região e se manter como lideranças do Movimento. Por isso, havia sempre uma preocupação em demonstrar nesses espaços coletivos sinais claros da condição de índio. Para tanto, além de se preocuparem em exibir traços culturais como uso da língua - embora fossem apenas algumas poucas palavras - as bebidas e as danças, os índios que assumiam cargos na coordenação do Movimento, utilizavam em seus discursos, tanto para outros índios no âmbito do Movimento, quanto "para fora" a palavra: 
"parente", cujo sentido era subtrair esses conflitos do campo das relações interétnicas, buscando dar ao Movimento uma unicidade necessária para a articulação das lutas e reivindicações indígenas na região e a legitimidade dos representantes, tanto interna como externamente.

c) Viagens de Articulação. As viagens das lideranças pelas aldeias se intensificaram e ganharam o nome de "Viagens de Articulação" no início dos anos de 1990 quando o Movimento se expandiu na região e passou a se articular mais permanentemente com o Movimento Indígena fora da região, sobretudo com a Coiab (Coordenação das Organizações Indígenas da Amazônia Brasileira), mas também, com o indigenismo articulado principalmente pelo Cimi. Devido à extensão geográfica da área abrangida pelo Movimento, às dificuldades de comunicação e ao aumento do volume de informações adquiridas a partir da articulação com o movimento indígena nacional e regional, criou-se a necessidade das "Viagens de Articulação", que ocorriam em cada região (Solimões e Japurá, depois também Jutaí e Juruá) uma vez por ano. Participavam dessas viagens: a coordenação da Uni-Tefé, membros da Pastoral Indigenista e representantes dos professores, mulheres e um tuxaua. A equipe visitava todas as aldeias de uma determinada região, permanecendo em cada uma delas, em média, dois dias. $\mathrm{Na}$ oportunidade, realizavam reuniões onde relatavam as atividades da Uni-Tefé; prestavam contas relativas aos projetos financeiros; informavam sobre a política indígena e indigenista dentro e fora da região; escutavam as necessidades e as críticas das aldeias e discutirem formas de resolver as tensões e os problemas.

Pudemos constatar, nos relatórios dessas viagens e nas observações de campo realizadas entre 1992 e 1995, algumas tensões entre as aldeias e a coordenação da Uni-Tefé. Tais tensões normalmente eram oriundas da forma como cada aldeia ou grupo indígena entendia o trabalho da Uni-Tefé e o papel da coordenação. Em muitos momentos pude observar aldeias e indígenas, em particular que normalmente não participavam das atividades do Movimento, cobrarem da coordenação da Uni-Tefé ações assistencialistas (doações de combustível e de objetos para as aldeias) entendendo que esta era uma função da Uni-Tefé. Essas mesmas tensões se davam também no âmbito das aldeias, onde os tuxauas eram pressionados a estabelecer relações paternalistas e assistencialistas com as comunidades e com o Movimento.

Podemos aventar, contudo, que essa forma de conceber o papel da UniTefé está relacionada à história de relação dessas aldeias com os patrões, com 
os comerciantes, com as autoridades políticas, com a igreja etc. O Movimento Indígena em Tefé até o final dos anos 90 esteve muito ligado não somente às orientações políticas do Cimi local, mas, sobretudo, à sua infraestrutura (casa, barco, escritório), sua assessoria e intermediação de financiamento de projetos. E embora o Cimi possuísse outra orientação política, diferente dessas práticas assistencialistas, baseada na perspectiva da "autonomia dos povos indígenas" - explícito nos documentos da entidade -, que pressupõe, nesse caso concreto, uma independência financeira e administrativa dos índios e suas organizações diante das velhas estruturas de dominação regional, isso se dava muito no âmbito do discurso, tendo muitas dificuldades de se concretizar em termos práticos pelas próprias características históricas das relações entre os índios e a Igreja na região. Daí também a dificuldade das aldeias em separar o Movimento Indígena das antigas formas de paternalismo e assistencialismo existentes na região, como aquelas praticadas pelos antigos patrões e por determinados políticos regionais.

Essas questões foram objeto de avaliação na Assembleia Regional do Solimões, realizada em setembro de 1994. Na oportunidade os índios discutiram as dificuldades financeiras enfrentadas pela Uni-Tefé e a pouca participação dos índios nas reuniões por ocasião das Viagens de Articulação, o que era lido pelo Movimento como baixa credibilidade da Uni-Tefé diante das aldeias. Depois da Uni-Tefé ter relatado os problemas e solicitado ajuda das aldeias para a continuação dos trabalhos, Lourival, tuxaua da aldeia Marajaí, assim se expressou:

(...) Então o pessoal da Uni-Tefé diz que não tem grana e eu acredito. Então eles devem ver se continuam com as viagens ou não. Eu acredito no que eles falaram, mas o povo não acredita. Mas se vocês quiserem fazer uma grande reunião em Marajaí eu aceito. Aí vocês vão falá isso lá diretamente pro povo, pra eles acreditarem...

(...) Pra vê se eles entendem o que é Uni-Tefé. Tem gente que não sabe o que é Uni-Tefé! Não sabe o que é Cimi. Dizem: - agora, eu sei o que é a Funai porque já me deu alguma coisa.

Pois é, eu queria que vocês falassem isso lá, no meio do povo. Por que se eu falá eles não acreditam em mim. Hoje, já não é como antigamente, que o tuxaua dizia: - você faz isso e o povo tinha que fazer. (...) Apenas, nós somos já, como se diz, só já o sumo da nação, não é troco que 
morreu na mata. Nós já provamos, já sentimos o gosto do branco no nosso meio. Então por isso que é muito ruim. Ali no Jaquiri nem tanto porque ali é tudo parente, cunhado, irmão... Mas em Marajaí tem mistura de tudo jeito. Se fosse só os Mayoruna, só meu irmão, ninguém estava desse jeito... (V ASSEMBLEIA GERAL DA UNITEFÉ, 1994).

$\mathrm{Na}$ sua fala Lourival convoca a Uni-Tefé para discutir esses problemas com as aldeias e justifica o desconhecimento e a falta de interesse da população de Marajaí em relação à Uni-Tefé e à presença de moradores que não eram Mayoruna. Nessa época, Marajaí estava realizando um esforço para retirar moradores que não fossem indígenas ou que não obedecessem às normas da aldeia. No discurso, Lourival mostra que o contato com os brancos trouxe mudanças na relação dos Mayoruna com seu tuxaua. Mas, embora esse discurso traga elementos importantes para a análise das relações interétnicas entre índios e brancos na região, pode esconder também fatos e questões novas que as antigas lideranças indígenas não queriam ver ou não poderiam admitir, sobretudo, em momentos em que os índios estavam reunidos para afirmar e reforçar as lutas indígenas.

$\mathrm{Na}$ mesma oportunidade, André Cruz definiu o que seria o papel da Uni-Tefé dentro do Movimento Indígena: ... A organização Indígena não é para fazêe projeto financeiro para aldeias, não é pra doá machado, terçado, nem dá dinbeiro, mas pra reivindicá os problemas e formar as lideranças... (V ASSEMBLEIA GERAL DA UNI-TEFÉ, 1994). Essa formação das lideranças era realizada através de vários cursos e encontros e de pronunciamentos na Rádio Educação Rural de Tefé.

d) Cursos e Encontros. A Uni-Tefé promoveu desde o início dos anos 1990, vários cursos e encontros anuais para professores, agentes de saúde, mulheres e parteiras indígenas. Nas propostas de conteúdos são perceptíveis duas preocupações: uma, de promover a formação técnica através dos conhecimentos da sociedade ocidental - especialmente no caso dos agentes de saúde e professores - e, outra, que buscava articular esse "novo conhecimento" com o conhecimento tradicional dos povos indígenas. Assim, encontramos com muita frequência nos relatórios desses cursos e encontros, as expressões: "resgate da medicina tradicional"; "resgate da língua"; "resgate dos conhecimentos tradicionais" etc. 
Em muitos casos e em especial nos encontros de professores e agentes de saúde, esses eventos também serviam como espaços de articulação do Movimento e de tomada de decisão dentro de cada área específica. Por isso, a coordenação da Uni-Tefé acompanhava sempre todos esses cursos e encontros.

e) Os Programas de Rádio. Desde o início dos anos 1980 as lideranças indígenas começaram a participar como entrevistados no programa de rádio "A voz do Parente" levado ao ar pela Pastoral Indigenista de Tefé, uma vez por semana com duração de 30 minutos. Esse Programa era estruturado da seguinte maneira: 1. ${ }^{a}$ parte, uma saudação inicial para todas as aldeias; $2{ }^{a}$ parte, uma música popular que tematizava a questão indígena ou as lutas populares de modo geral; $3{ }^{a}$ parte, leitura de uma matéria sobre algum assunto da política indigenista veiculada pela mídia, uma história ou um mito indígena; $4 .{ }^{a}$ parte, uma entrevista ou pronunciamento indígena; $5{ }^{a}$ parte, notícias regionais e nacionais sobre o movimento indígena; $6 .^{a}$ parte, avisos para as aldeias; $7 .^{a}$ parte, um assunto de interesse das aldeias, discutido por dois personagens que utilizavam técnicas teatrais que misturavam drama e comédia numa linguagem popular acessível para as aldeias. Cada etapa era intercalada com uma música popular. Durante a pesquisa nos arquivos da prelazia foram encontradas dezenas de fitas com esses programas e com entrevistas e pronunciamentos indígenas.

A utilização desse espaço na mídia local é relevante porque proporcionava à coordenação do Movimento uma via de comunicação direta com as aldeias de toda a região de Tefé. Mesmo aqueles grupos que até metade dos anos de 1990 não participavam do Movimento, como os Madijá do rio Juruá, escutavam a "voz" das lideranças pela rádio. Em 1992, quando estivemos na aldeia Kumaru do povo Madijá, no rio Juruá, eles disseram que sempre ouviam pela rádio o sr. André e gostariam muito de conhecê-lo.

A rádio também era usada para mandar avisos para as aldeias sobre a programação da Uni-Tefé, comunicação e avisos entre as próprias aldeias. A participação constante nesses programas tornou as lideranças do Movimento conhecidas mesmo em aldeias aonde elas nunca chegaram. Contudo, esse espaço de comunicação não deixa de ser também "um espaço de contradição dentro do Movimento", uma vez que, se por um lado, contribuía para tirar os índios do "isolamento" provocado pela falta de acesso aos meios de comunicação numa região tão vasta geograficamente e isolada da capital do Estado, por outro lado, acabou contribuindo para o fortalecimento de um certo tipo de liderança, 
geralmente mais jovem, que dominava mais a língua portuguesa e claro que estava próxima da cidade de Tefé, da coordenação do Movimento Indígena e da própria Pastoral Indigenista. Essas lideranças novas, aos poucos, vão dominar as técnicas de locução radiofônica e mais tarde assumir o Programa de Rádio.

f) As Radiofonias. A partir de 1998, por meio de financiamento externo a Uni-Tefé conseguiu colocar em cada aldeia da região uma radiofonia, que passou a ser o principal veículo de comunicação entre a coordenação e as aldeias e destas entre si. Com isso, diminuíram as viagens de articulação dispendiosas financeiramente para o Movimento. Por intermédio desse equipamento a coordenação consegue acompanhar diariamente tudo o que ocorre nas aldeias, relativo à questão da educação, cuidados com a saúde, vigilância territorial etc., bem como articular encontros e reuniões do Movimento Indígena.

\section{Considerações finais}

Desde o início do Movimento Indígena em Tefé, duas expressões distintas foram utilizadas com muita força em diferentes momentos da história do Movimento: se encostá e articulá. Encostar tem o sentido de "pôr junto", "aproximar", "parar", "estacionar", tendo sentido de "fazer-se dependente", mas também de "firmar-se", "apoiar-se" em algo ou em alguém por um tempo para se restabelecer, ganhar força e apoio.

Por ocasião do 1. Encontro de Líderes Indígenas da Prelazia de Tefé, 1980, aldeia Miratu, ao relatar as dificuldades de sobrevivência, o tuxaua Miranha, Adriano Pereira, propôs: "Será que a gente se encostando do lado deles, eles não consegue alguma coisa pra nós? [...] Eu vou me encostá do lado da Prelazia de Tefé. Pode ser que melhore alguma coisa" (MACIEL, 2003, p. 145). De fato, a partir de então, o Movimento Indígena passou a encostar-se na Prelazia de Tefé que, por sua vez, tinha também interesse em apoiar os índios. $\mathrm{Na}$ década de 1980, tanto dentro da igreja quanto fora dela, havia um crescente movimento de apoio à causa indígena no Brasil, que viria a possibilitar um grande avanço dos direitos indígenas na Constituição de 1988. Essa iniciativa indígena somada ao apoio da Igreja por meio, sobretudo, do Cimi vai desembocar nos primeiros encontros e reuniões de mobilização indígena em Tefé.

Mas, para sair de encontros esporádicos que reuniam poucas aldeias, para assembleias gerais e regionais com a participação de todos os grupos indígenas da 
região, encontros de professores, de agentes de saúde, de mulheres, de parteiras, criação da Uni-Tefé e de toda uma estrutura organizacional e de comunicação, os índios da região de Tefé tiveram que se articular. Articular passou a ser uma palavra de ordem do Movimento Indígena na década de 1990 e se dava em vários níveis das relações sociais: entre as aldeias; entre os diferentes grupos étnicos; entre as lideranças e as aldeias; com a Igreja e com o Movimento Indígena regional e nacional. Mas, o que era articulado? Os interesses comuns dos índios: melhoria das condições de saúde, educação; conquista das terras; o reconhecimento pela sociedade regional dos direitos dos povos indígenas. Assim, todos os meios de comunicação e articulação disponíveis foram utilizados: na proa da canoa ou do barco, onde nas viagens de articulação jogava-se dominó e tomava-se açaí, trocavam-se ideias sobre a questão indígena na região; nas assembleias e encontros discutiam-se os problemas e encaminhavam-se soluções; nos programas de rádio ouvia-se música, mas também notícias e mensagens do Movimento Indígena. O crescimento do Movimento colocou sempre presente o desafio da comunicação e da articulação dos interesses indígenas entre as aldeias e delas com a Uni-Tefé. Uma articulação política que não poderia ser feita apenas "na proa da canoa", nem tão pouco fora dela, mas a partir dela.

\section{6- Notas}

1. Até 1982, quando Uarini foi emancipado, Miratu pertencia ao município de Tefé e na estrutura administrativa do município era identificada como "comunidade" categoria genérica que designa as vilas e povoações da região - e, não como "aldeia", termo específico para os agrupamentos indígenas.

2. Sobre a fundação do MEB, sua vinda para Tefé e as características de sua atuação confira: MACIEL, Benedito. Afirmação étnica e movimento indígena em Tefé: o caso dos Cambeba. In: SOMANLU - Revista de Estudos Amazônicos, ano 5, n.o 1, jan./jun. 2005, p. 159 (nota 4).

3. A caicuma é uma bebida fermentada feita geralmente de mandioca, mas na região de Tefé a encontramos, também feita de pupunha. O pajauarú é também uma bebida feita de mandioca cujo tempo de fermentação é maior que da caiçuma, sua textura é mais fina, é fermentada e contém maior concentração de álcool. Os índios do Médio Solimões só fazem em ocasiões especiais. No Japurá e no Juruá é mais comum. O chibéé bem mais conhecido na região, e consiste na mistura simples de água e farinha de mandioca. 


\section{Referências}

CARDOSO DE OLIVEIRA, Roberto (1976). Identidade, Etnia e Estrutura Social. São Paulo: Pioneira.

CARDOSO DE OLIVEIRA, Roberto (1978). "Problemas e hipótese relativos à fricção interétnica". In: Sociologia do Brasil Indígena. Rio de Janeiro/ Brasília: Tempo Brasileiro/UnB, p. 83-131.

CORDEIRO, Lino. Entrevista gravada em 27/12/2002. Entrevistador: Benedito Maciel. Cidade de Uarini-Amazonas. Uma fita cassete, 120 minutos. Entrevista concedida ao projeto: "Identidade como articulação de novas possibilidades: um estudo da reafirmação étnica dos Omágua da Amazônia brasileira (1980-2000)". PPGSCA/Ufam, 2002.

FALHAUBER, Priscila. O Navio Encantado: etnia e alianças em Tefé. Belém: Museu Goeldi, 1987b.

FALHAUBER, Priscila. A Reinvenção da identidade indígena no Médio Solimões e no Japurá. In: ANUÁRIO ANTROPOLÓGICO/96, Rio de Janeiro: Tempo Brasileiro, 1997, p. 83-101.

FALHAUBER, Priscila. O Lago dos Espelhos: etnografia do saber sobre a fronteira em Tefé/Amazonas. Belém: Museu Paraense Emílio Goeldi, 1998.

FALHAUBER, Priscila (Org.). Entrosando: questão indígena em Tefé. Belém: Museu Paraense Emílio Goeldi, 1987.

MACIEL, Benedito. Identidade como Articulação de novas possibilidades: etnohistória e reafirmação étnica dos Cambeba na Amazônia brasileira. Dissertação - (Mestrado) - Manaus: Universidade Federal do Amazonas, 2003.

MACIEL, Benedito. "Afirmação étnica e movimento indígena em Tefé: o caso dos Cambeba". In: SOMANLU - Revista de Estudos Amazônicos, ano 5, n. 1, jan./jun, 2005. 
V ASSEMBLEIA GERAL DA UNI-TEFÉ (setembro de 1994). Vários depoimentos. Arquivo da Pastoral Indigenista da Prelazia de Tefé. Uma fita cassete, 120 minutos. (transcrição: Benedito Maciel, abril de 2003).

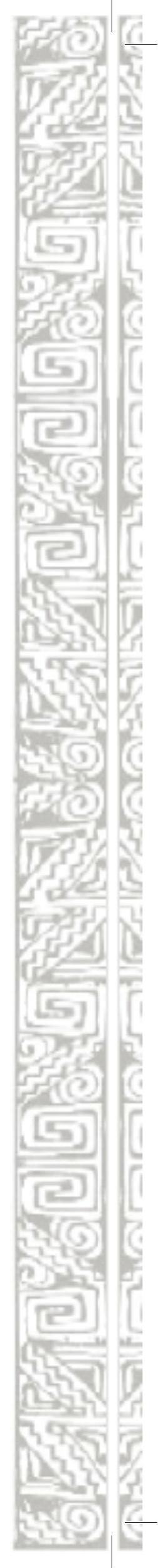

